\title{
The Role of Glycosylation in Receptor Signaling
}

\author{
Brian J. Arey
}

Additional information is available at the end of the chapter

http://dx.doi.org/10.5772/50262

\section{Introduction}

Glycosylation is an important and highly regulated mechanism of secondary protein processing within cells. It plays a critical role in determining protein structure, function and stability. Structurally, glycosylation is known to affect the three dimensional configuration of proteins. This is of particular importance when considering protein-protein interactions such as those that occur between protein ligands and their cognate receptors or in the creation of other large macromolecular complexes. Many secreted proteins, such as hormones or cytokines, are glycosylated and this has been shown to impact in determining their activity when bound to receptors. Changes in these complexes result in alterations in how they recruit, interact and activate signaling proteins (e.g. G proteins). Additionally, signaling proteins are also glycosylated and this has distinct effects on their function. Ultimately, these effects help determine which signaling pathways are activated within the cell (Figure 1). Thus, glycosylation plays a key role in determining the cellular response to exogenous factors. This chapter will provide an overview of how glycosylation of ligands, their receptors, and signaling proteins affects signal transduction in mammalian cells by discussing specific examples of how receptor signaling is regulated by glycosylation.

\section{Role of glycosylation in protein function}

Although carbohydrates added to proteins are known to be highly flexible and mobile within the constraints of the glycoprotein, they are known to provide a key stabilizing force for proteins within their microenvironments. Of particular importance is the role that carbohydrates play in achieving the proper three dimensional conformation of glycoproteins $(1,2)$. As the carbohydrates are added to the nascent protein within the endoplasmic reticulum, carbohydrates (monosaccharides) are added to the protein on specific amino acid residues. Glycosylation has been reported on 8 different amino acids with the most common residue for carbohydrate addition being asparagine (N- 
glycosylation). This process can aid in the final protein product folding correctly into its three dimensional, biologically active conformation. However, this is not the case for all glycoproteins although it has been noted for a significant number (2). Interestingly the mechanism of adding these sugar residues is complex and not fully understood but is known to require several enzymes and is physiologically regulated. This suggests that glycosylation, as well as other secondary protein processing, is vital to the biological function of these proteins.

\section{or}

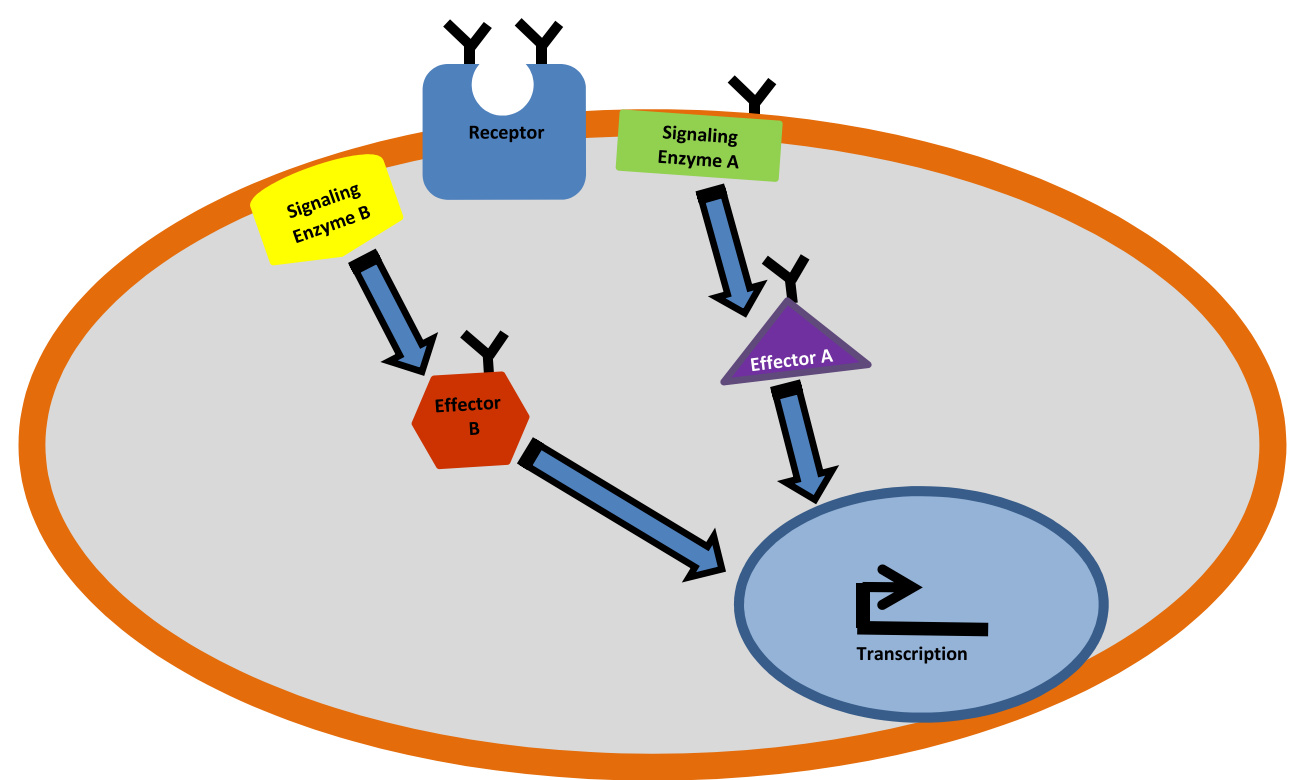

Figure 1. Regulation of receptor-ligand signaling by glycosylation. Glycosylation occurs at every level of the receptor signaling mechanism and therefore can impact the biological responses induced by receptor-ligand binding. Glycosylation (black lines) can occur on the ligand itself, the receptor, as well as on key signaling enzymes and effector proteins (hexagon,triangle). All of which play an improtant role in driving the biological responses in the cell.

In addition to its effects on driving correct folding of glycoproteins, glycosylation also has other effects on the physicochemical properties of these proteins. These effects help to determine the glycoprotein's overall energy and this can affect many of the biological functions that the protein performs (for a more detailed review see (3)). For example, glycosylation is well known to play a role in modulating thermostability of proteins as well as the overall charge. Of particular interest to the development of new therapies is the role that glycosylation plays in affecting protein-protein interactions. Intermolecular association that occur between protein ligands and their cognate receptors or between activated receptors and their intracellular signaling machinery have been shown to be modulated by 
the presence of glycosylation (4). Many examples exist that suggest that glycosylation of either a receptor or its ligand aids in determining the resulting biological responses. The primary mechanism for these effects lies in the ability of carbohydrates to modulate the overall energy state of the protein $(2,3)$.

In terms of thermostability, studies of various glycoproteins have focused on the thermodynamics of select placement or displacement of glycosylation on proteins (2). These studies have revealed that addition of even a single monosaccharide to a protein can significantly impact the fluctuation of that protein between folded and unfolded states (3). Through detailed NMR evaluation and use of statistical tools it has been found that certain commonalities exist for the placement of carbohydrates on protein and predict a functional role for these sites in stabilization of protein structures. One such study has found that glycosylation can occur on almost any part of a protein's structure but that bends or turns in the structure are preferred. Similarly, it has been found that glycosylation of proteins has a greater impact at less structured regions of a protein highly suggest that glycosylation plays a key role in protein stabilization $(2,3)$. In addition to aiding the stablization of proteins in a microenvironment, glycosylation has also been found to play a key role in stabilizing glycoproteins in the macroenvironment through alteration in half-life. There are numerous reports that the presence of polysaccharides added as secondary protein processing prolongs the half-life of these proteins including antibodies, hormones and cytokines (5).

\section{Role of glycosylation in receptor function}

\subsection{Viral coat proteins}

One of the best studied glycoproteins is the HIV viral coat protein, GP120. The description of the role of viral glycoproteins in host-virus interactions have been studied extensively and reviewed in detail elsewhere (5). However, this important interaction deserves mention. The GP120 protein is integral to the initiation of contact between the HIV virus particle and its host cell by mediating the adhesion of the viral particle to the host cell surface. It is a heavily glycosylated protein owing nearly half of its mass to the presence 27 glycosylated residues (5). This protein acts as part of a co-receptor complex with the host cell CD4 protein. Association between CD4 and GP120 leads to conformational changes in these proteins that ultimately lead to membrane fusion between the host cell and the virus particle. The presence of this glycosylation acts as a natural barrier to defending immune cells and antibodies such that it is difficult for the natural immune system to recognize and target the HIV virus for elimination.

\subsection{Interleukins}

Interleukins are secreted glycoproteins of the immune system that communicate both positive and negative regulatory signals to the various cellular and components that make up the innate and acquired immune responses. Interleukins and other cytokines exert 
their actions on their target cells through interactions with specific receptors. Most cytokines like interleukins are found in their mature state as glycosylated proteins. In the case of these important glycoprotein modulators, both $\mathrm{N}$-linked and O-linked glycosylation has been described (6). The role of glycosylation in affecting cytokine function has been of interest from both the protein ligand and the receptor perspectives. Due to the large number of different cytokines, for the purposes of this chapter we will focus on Interleukin 5 (IL5).

IL5 is an important immune cytokine that is released from T-cells and induces activated Bcells into antibody producing cells. In addition, IL5 also acts as a differentiating factor for eosinophils. From a clinical perspective, the role of IL5 is important for immune diseases that involve hyperproliferation and invasion of eosinophils, such as in asthma (7). IL5 works as a homodimer that binds specifically to its membrane-bound receptor (IL5R). In the case of IL5, chemical digestion of either the N-linked or O-linked sugar residues on recombinant hIL5 had profound effects on the biological activity of the cytokine in terms of its ability to stimulate release of IgM from BCL1 cells (8). Removal of the N-linked glycosylation on IL5 improved potency of the cytokine by approximately 3 fold. Interestingly, removal of the Olinked sugars led to an approximate 10 fold improvement in potency of IL5 which was equivalent to fully deglycosylated IL5 (8). In this same study, the authors also demonstrate that the N-linked glycosylation but not the O-linked glycosylation significantly improved the thermostability of IL5 in vitro. These data suggest that both $\mathrm{N}$-linked and O-linked glycosylation play important roles in the biological activity of IL5.

The IL5R is composed of two subunits, the IL5R $\alpha$ and $\beta c$ subunits. Mechanistic studies have revealed that IL5 induces biological activity through a two step process in which IL5 binds to the IL5 $\alpha$ subunit leading to interaction with the preformed $\beta c$ subunit $(9,10)$. The $\beta c$ then induces the signaling cascade within the target cell through activation of a kinase cascade by way of associated JAK kinases. The IL5 $\alpha$ subunit is highly glycosylated having $4 \mathrm{~N}$ glycosylation sites $\left(\mathrm{Asn}^{15}, \mathrm{Asn}^{111}, \mathrm{Asn}^{196}\right.$ and $\left.\mathrm{Asn}^{224}\right)$ in the extracellular region $(11,12)$. Complete removal of the glycosylation of IL5 $\alpha$ leads to a loss of ligand binding. More detailed studies of the contributions of the N-glycosylation sites on IL $5 \alpha$ revealed that Asn ${ }^{196}$ is required for ligand binding (9). Loss of the other three sites by mutation had no effect on IL5 affinity and biological activity (B-cell proliferation assay). Interestingly, mutation of $\mathrm{Asn}^{196}$ led to a complete loss of binding and biological activity, suggesting that glycosylation of that residue is absolutely required for IL5 recognition (9).

IL5R $\beta \mathrm{c}$ subunit is also glycosylated. This protein interacts with a number of cytokine receptors including IL5 $\alpha$, interleukin $3 \alpha$ (IL3 $\alpha$ ) and granulocyte-macrophage colonystimulating factor $\alpha$ (GM-CSF $\alpha$ ). Therefore, the $\beta$ c protein is a common signal transducing partner to many cytokine receptors. The $\beta$ c protein contains an $\mathrm{N}$-linked glycosylation site at $\mathrm{Asn}^{328}$. Conflicting reports have been published suggesting that glycosylation of $\mathrm{Asn}^{328}$ is either required for signaling activity of the $\beta c$ subunit or not required. However, a recent publication by Murphy et al, suggests strongly that glycosylation at $\mathrm{Asn}^{328}$ does not play a role in either ligand binding or receptor activation. 


\subsection{Glycoprotein hormone family}

The reproductive hormones called gonadotropins (luteininzing hormone (LH) and folliclestimulating hormone (FSH)) are important to proper regulation of reproduction. These proteins are found in the circulation as alpha subunit and beta subunit heterodimers that contain multiple glycosylation sites on both subunits $(13,14)$. Along with the thyroidstimulating hormone (TSH), they comprise the glycoprotein hormone family. Interestingly, the degree of glycosylation added to these hormones varies depending upon the physiological state and therefore, they are found in the plasma as a series of isoforms that vary in glycosylation complexity.

Historically, it has been accepted that glycosylation complexity has an impact on the overall acidity of each isoform with more complex variants (higher degree of terminal sialylation and sulfation) possessing more acidic isoelectric points $(\mathrm{pI})(15,16)$ with less terminally sialylated /sulfonated isoforms more basic in pI. Chromoatofocusing has been used as a way of purifying these differently glycosylated isoforms. Recently though, Bousfield has generated data demonstrating that chromatofocusing does not separate isoforms on the basis of glycan structure suggesting that the isoelectric point of gonadotropins is not completely determined by the glycosylation structure (17). Nevertheless, the physiological significance of these glycosylated variants is suggested by data demonstrating that the degree of glycosylation that occurs within the anterior pituitary synthetic cells is regulated by exogenous factors including ovarian steroids $(18,19)$. Tight regulation of this secondary protein processing of glycoprotein hormones suggests an important physiological role for the presence of glycosylated variants of TSH, LH and FSH. Numerous reports have detailed the effects of partial or complete deglycosylation on action of these hormones $(14,20,21)$. The data in this area are varying with some noting no effects on binding (14, 22-24) and others noting increased binding affinity $(21,25)$. However, recent work in this area using more sophisticated separation techniques strongly suggest that hormone glycosylation does play a significant role in receptor binding (25). There is a significant effect on signaling. Indeed, using a baculovirus expression system to create partially glycosylated isoforms of FSH has shown that glycosylation can change the pharmacological properties of the hormone via alterations in interaction of the FSH receptor with the G protein signaling machinery $(13,24)$. In addition, numerous reports have found a distinct difference in the observed bioactivity of basic isoforms of glycoprotein hormones as compared to acidic isoforms $(13,14)$.

The glycoprotein hormone receptors are G protein-coupled receptors (GPCR) (26). These receptors are characterized by long amino-terminal extracellular domains (>300 aa) that are required for binding of ligand, seven lipophilic, membrane-spanning domains and relatively short, cytoplasmic carboxy-terminal tails $(27,28)$. The extracellular domains of the glycoprotein hormones are characterized by numerous leucine rich repeats (LRR) that have been shown to be important to binding of the receptors to their respective ligands (27). Similar to their hormone ligands, glycoprotein hormone receptors also contain sugar 
residues on their extracellular domains. Studies of the contribution of this glycosylation via mutation of the Asp residues acting as glycosylation sites has found that the glycosylation is responsible for proper folding of the receptor during protein synthesis $(29,30)$. This is more so for TSHR and FSHR than for LH/hCGR (31). Overall, the glycosylation state of the receptor does not seem to have an effect on ligand binding affinity or activation of signal transduction pathways (32).

\section{Glycosylation of signaling proteins}

\subsection{Adenylate cyclase}

In addition, to determining ligand-receptor interactions in some systems, glycosylation can also play a role in regulating intracellular signaling proteins. Adenylate cyclase is a key enzyme that produces the second messenger cAMP from ATP. It is best described for its ability to be stimulated or inhibited by activation of heterotrimeric GTP binding proteins (G-proteins) following G-protein-coupled receptor (GPCR) binding to agonist. There are nine recognized adenylate cyclase isoforms and three general classes of membrane bound adenylate cyclases: the calcium activated family (AC1, AC3 and AC8), the calcium-inhibited family (AC5 and AC6) and the G-protein activated family (AC2, AC4 and AC7) (33). All nine adenylate cyclases are regulated by Gas and magnesium. The calcium activated family members respond to calcium in a calmodulin-dependent manner (33). The calcium-inhibited adenylate cyclases are inhibited by calcium at less than micromolar concentrations. The G-protein activated family responds to activation by $\mathrm{G} \beta \gamma$ subunits following GPCR agonist binding (33). In addition, splice variants of some forms of adenylate cyclases have been noted (34). Generally speaking, adenylate cyclases tend to be clustered together within cell membranes with other signaling components such as receptors and G-proteins in lipid rich domains such as those formed by the scaffolding protein caveolin-1 (35).

Several types of post-translational modifications to adenylate cyclases have been found to affect their activity; including nitrosylation, phosphorylation and glycosylation (36). In terms of glycosylation, regulation of several adenylate cyclase family members has been reported. N-linked glycosylation has been observed on the extracellular domains of some adenylate cyclases and for this reason there had been some controversy concerning the functional role it played in enzyme activity. This was mainly due to the fact that adenylate cyclase interacts with its protein partners within domains found on the cytoplasmic side of the enzyme. However, deglycosylation using metabolic inhibitors or site-directed mutants have revealed a critical role for glycosylation in adenylate cyclase activity.

Glycosylation of Type 8 adenylate cyclase (AC8) has been found on two of its three isoforms (34). These glycosylation sites are found the extracellular surface of two of these isoforms (AC8-A and AC8-C) but not on the AC8-B isoform. This is presumably due the excision of a portion of the extracellular domain between transmembrane spans 9 and 10 
in this isoform that contains the N-linked glycosylation site. Recent studies of the role of these glycosylation sites in AC8 have shown that they are critical to localization of the enzyme to the lipid rich rafts in membranes (37). Thus, potentially determining function of AC8 in cells where it is expressed. This would imply a differential localization and functional role for AC8-B.

Glycosylation of AC6 is required for response to several stimulators of AC activity since mutagenesis or glycosylation inhibitors affect AC6 response to forskolin and G-proteins (38). The other member of the calcium-inhibited ACs, AC5, has two putative glycosylation sites but it is still unclear as to whether these sites are glycosylated (36).

The other member of the adenylate cyclase family of enzymes is adenylate cyclase 9 (AC9). This particular adenylate cyclase is the most divergent in terms of sequence from the other known ACs. AC9 activity is regulated by G-proteins and by protein kinase C. Gs stimulates activation of AC9, while Gi and PKC have been shown to negatively regulate AC9. AC9 is glycosylated on two sites; removal of the N-linked glycosylation on these sites by site directed mutagenesis did not affect the stimulation of AC9 by forskolin (39). However, removal of the glycosylation sites on AC9 did affect Gs -mediated stimulation of AC9 in HEK cells (39).

Taken together, these data reveal an integral role for glycosylation in determining and modulating adenylate cyclase localization, protein-protein interactions and function.

\subsection{Insulin receptor signaling}

The insulin receptor is a hetero-tetrameric receptor tyrosine kinase that is well known for its regulation of glucose metabolism. The insulin receptor contains numerous glycosylation sites that include both $\mathrm{O}$ - and N-linked glycosylation. The glycosylation of the insulin receptor is metabolically regulated since glucose deprivation has been shown to preferentially affect O-linked but not $\mathrm{N}$-linked glycosylation of the receptor. Since insulin is a master metabolic regulator, this suggests that glycosylation plays a significant physiological/pathophysiological role in insulin action (40). Indeed, mutational analysis of the potential O-glycosylation sites on the insulin receptor has revealed significant effects on functioning of the receptor. This may be due to the fact that these sites tend to be near phosphorylation sites on the receptor important to regulation of the receptor activity (41). Removal of glycosylation on the receptor does not affect receptor binding but partial loss of glycosylation leads to a constitutively active kinase activity of the receptor. In pancreatic $\beta$ cells, an increase in O-linked glycosylation results in an increased $\beta$-cell apoptosis (42). Downstream of the insulin receptor, an increase in O-linked glycosylation leads to decreased phosphorylation of key insulin signaling molecules, insulin receptor substrate 1 (IRS1) and 2 (IRS2), Akt and FOXO1a (42). These data demonstrate that glycosylation is a key regulator of insulin receptor function. Taken together with the observation that the glycemic state of the cell can modulate the pattern of glycosylation of the receptor $(40,43)$, 
these data suggest that insulin receptor activity is dynamically regulated within insulin target cells and is sensitive to the metabolic state of the cell.

In addition to the insulin receptor, insulin signaling molecules have been found to be regulated by glycosylation. Specifically, IRS-1 and $\beta$-catenin, two important downstream effectors of insulin receptor activation, are known to be glycosylated. Furthermore, it is thought that shunting of glucose metabolism through the hexosamine biosynthetic pathway leads to a general increase in O-linked glycosylation of nuclear and cytoplasmic proteins through increased substrate for O-linked $\mathrm{N}$-acetylglucosamine transferase (41). Increased glycosylation of IRS and $\beta$-catenin and insulin receptor have been linked with decreased phosphorylation and activity of these key metabolic enzymes. The end result of this process is loss of cellular insulin sensitivity (41).

\section{Glycosylation in receptor pharmacology}

\subsection{Gonadotropins}

It is now well documented that most GPCRs have the capability of signaling via multiple pathways in a given cell type. For many years, this hypothesis was poorly understood and was thought to be an artifact of recombinant cell systems. With the recent development of allosteric agonists, antagonists and modulators to GPCRs, more light has been shed on this concept; e.g., direct targeting of specific signaling pathways has been demonstrated for various ligands $(4,44)$. This phenomenon has most recently been termed, biased signaling. Simply put, the concept of biased signaling describes the ability of ligands to direct specific and distinct biological responses via activation of select signaling pathways in a ligandspecific manner (4). There are many receptors that are known to associate with multiple naturally occurring ligands. The gonadotropins, LH and FSH are excellent examples of this phenomenon. Since varying glycosylation of gonadotropin isoforms is known to alter their physicochemical properties, one can consider gonadotropin isoforms as different ligands with potentially subtle, but unique association with their cognate receptors $(4,24)$. In addition, interaction of these diverse ligands with the receptor would result in multiple ligand-receptor conformations, which in turn lead to the observed activation of differing biological signaling pathways for LH, hCG and FSH $(13,45,46)$. Thus, it has been suggested that gonadotropin isforms are naturally occurring biased agonists for their receptors $(4,24)$.

The molecular basis for biased agonism lies in the stabilization of conformation(s) of the receptor which increases the affinity of the biased agonist-receptor complex for a distinct and specific signaling pathway over another (44). Since GPCRs primarily utilize G proteins as signal transducers, biased agonism would imply ligand-dependent preference of the ligand-receptor complex for a specific G-protein over another. Since GPCR signaling is not exclusive via G-proteins, biased agonism is not restricted to G-protein signaling, and recent descriptions of biased ligand-mediated activation of non-G-protein-dependent signaling of GPCRs have appeared, such as is the case with $\beta$-arrestin signaling. 


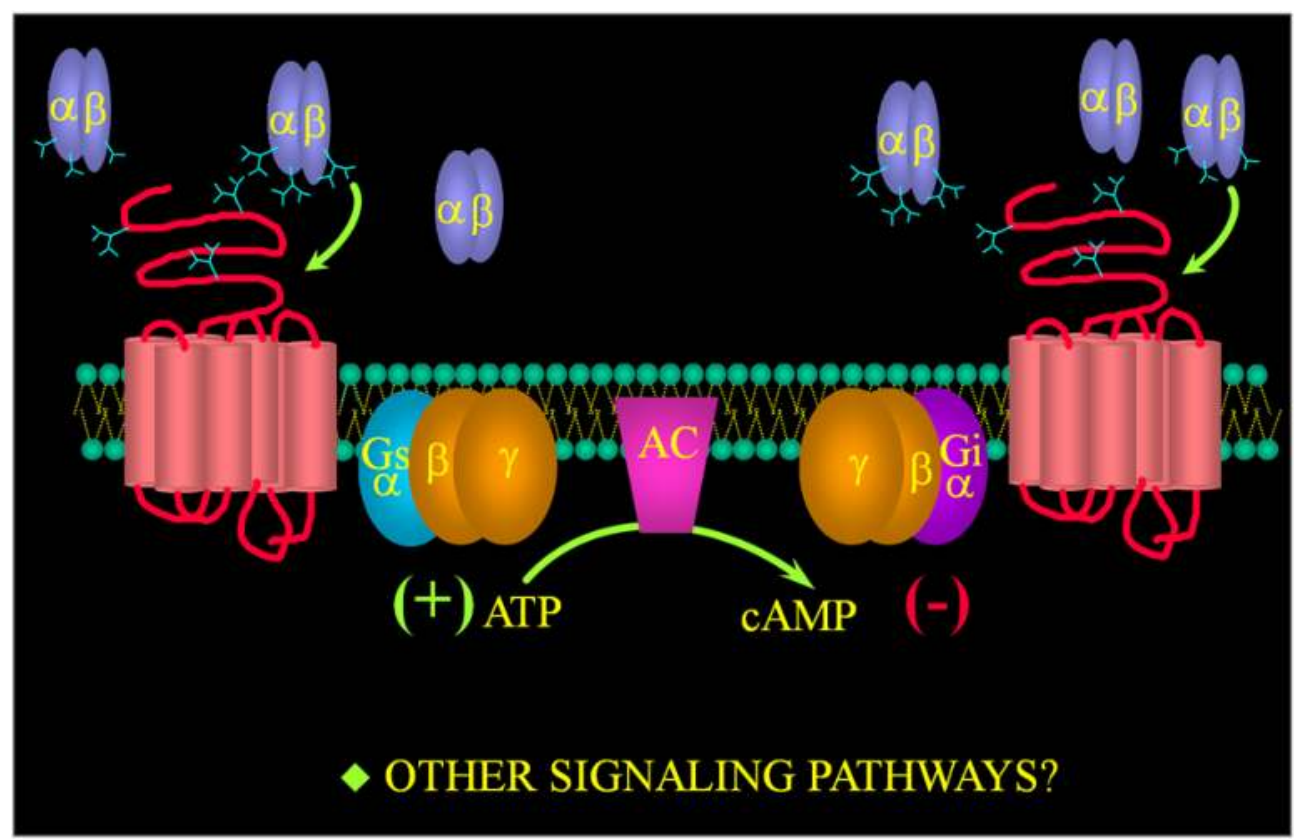

Figure 2. Glycosylated variants of gonadotropins are biased agonists at their receptors. Gonadotropins are secreted into the blood as isoforms that vary in the degree of complexity of glycosylation. Variations in glycosylation has been shown to be important to plasma half-life and receptor binding. It is now appreciated that these isoforms also impact the biological activity of the gonadotropins (4). In the case of FSH (depicted), glycosylated variants stabilize different conformations of the receptor-ligand complex. This leads to different affinities of the receptor-ligand complex for association with $G$ proteins. Highly complex, terminally sialylated FSH induces activation of Gs signaling pathways. Less complex glycosylation associated with terminal mannose leads to activation of both Gs and Gi signaling pathways. Deglycosylated FSH activates the Gi signaling pathway. Since the FSHR is also know to affect other signaling pathways, such as $\mathrm{Gq}$, these isoforms may also differentially activate $\mathrm{Gq}$ signaling as well.

For many years, FSH has been used as a model to understand the role of glycosylation in determining glycoprotein hormone function. Several years ago, we noted that differently glycosylated variants of hFSH could induce activation of both the Gs and Gi signaling pathways $(24,47)$. The phenomenon appeared as a bell-shaped concentration-response curve in in vitro assay systems for less glycosylated insect cell expressed hFSH (BV-hFSH). Pertussis toxin was found to block the down-turn in the dose-response relationship, indicating that the descending phase of the curve for the BV-hFSH was due to activation of $\mathrm{Gi}$ at higher concentrations of the hormone. These pharmacological relationships had been described previously for other receptors such as the catacholamines and adenosine receptors $(48,49)$. In the case of the insect cell expressed hFSH (BV-hFSH), glycosylation was terminated at short branched mannose residues, and the protein displayed a more basic migration pattern in chromatofocusing (Arey, unpublished data). Subsequent experiments using an ADP-ribosylation assay, along with immunoprecipitation and Western blotting 
of specific G-proteins, revealed that these pharmacological responses were definitively associated with activation of specific G-proteins (50). Taken together with in vivo effects of the different FSH preparations (4), these data demonstrate that the activities observed in signaling are directly translated into organ growth responses and illustrate the ability of the biased ligand (e.g., BV-hFSH) to elicit a different response pattern than that of the native ligand (phFSH) (Figure 2). Interestingly, similar glycosylation-dependent signal biasing has been noted for other secreted glycoproteins [e.g. IL22 and BMP6, (51, 52)] including LH/hCG $(53,54)$. Ligand glycosylation has also been suggested to be required for $\mathrm{LH} / \mathrm{hCG}$ receptor dimerization $(53,55)$. In the case of BMP6, detailed mutagenesis around key asparagine residues has revealed the importance of glycosylation in interactions with its receptor (52). In the case of IL22, a single fucose residue on Asn54 was shown to be required for full efficacy of the cytokine at its receptor. It is worth mentioning that the binding kinetics of the receptor were altered by more complex glycosylation at this site (51). Similar but more dramatic effects of glycosylation on binding kinetics have also been noted for erythropoeitin (56). These examples lay the foundation for the concept that a variety of related natural ligands talk to the receptor by inducing specific receptor conformations and that glycosylation plays a role in aiding in this stabilization, thus transducing specific signals that are unique to a given physiological state. Similar activities were ultimately discovered for other GPCRs (57). Therefore, from a mechanistic viewpoint, there is strong support for the notion that alteration of the glycosylation pattern on glycoprotein hormones leads to biased ligands that direct activation of one signaling pathway over another. The data support the notion that more basic isoforms of the gonadotropins bind with a higher affinity but are "less" bioactive. Therefore, different glycosylated variants may interact with the receptor in subtle, but unique ways to result in different signaling and biological responses . Overall, the data indicate that receptor signaling has evolved to convey complex regulatory signals in response to varying ligands which are dynamically adjusted to accommodate to external/internal influences and ultimately maintain homeostasis.

\section{Author details}

Brian J. Arey

Bristol-Myers Squibb Co, USA

\section{Acknowledgement}

This chapter is dedicated to my father, James, my first and most important mentor.

\section{References}

[1] Ruddon RW, Bedows E 1997 Assisted protein folding. J Biol Chem 272:3125-3128 
[2] Shental-Bechor D, Levy Y 2009 Folding of glycoproteins: toward understanding the biophysics of the glycosylation code. Curr Opin Struct Biol 19:524-533

[3] Shental-Bechor D, Levy Y 2008 Effect of glycosylation on protein folding: A close look at thermodynamic stabilization. PNAS 105:8256-8261

[4] Arey BJ, Lopez FJ 2011 Are circulating gonadotropin isoforms naturally occurring biased agonists? Basic and therapeutic implications. Rev Endocr Metab Disorders

[5] Meyer B, Moller H 2007 Conformation of glycopeptides and glycoproteins. Topics Curr Chem 267:187-251

[6] Chamorey A-L, Magne N, Pivot X, Milano G 2002 Impact of glycosylation on the effect of cytokines. A special focus on oncology. Eur Cytokine Net 13:154-160

[7] Foster P, Hogan S, Ramsay A, Matthaei K, Young I 1996 Interleukin-5 deficiency abolishes eosiniphilia, airways hyperreactivity and lung damage in a mouse asthma model. J Exp Med 183:195-201

[8] Kodama S, Tsulimoto M, Tsuruoka N, Suko T, Edno T, Kobata A 1993 Role of sugar chains in the in vitro activity of recombinant interleukin 5. Eur J Biochem 211:903-908

[9] Ishino T, Economou NJ, McFadden K, Zaks-Zilberman M, Jost M, Baxter S, Contarino MR, Harrington AE, Loll PJ, Pasut G, Lievens S, Tavernier J, Chaiken I 2011 A protein engineering approach differentiates the functional importance of carbohydrate moieties of interleukin-5 receptor. Biochemistry 50:7546-7556

[10] Ishino T, Harrington AE, Zaks-Zilberman M, Scibek JJ, Chaiken I 2008 Slow dissociation effect of common signaling subunit bc on IL5 and GM-CSF receptor assembly. Cytokine 42:179-190

[11] Cornelius S, Plaetinck G, Devos R, Van der Heyden J, Tavernier J, Sanderson C, Guisez Y, Fiers W 1995 Detailed analysis of the IL-5-IL5Ra interaction: Characterization of crucial residues on the ligand and the receptor. EMBO J 14:3395-3402

[12] Ishino T, Pasut G, Scibek J, Chaiken I 2004 Kinetic interaction analysis of human interleukin 5 receptor mutants reveals a unique binding topology and charge distribution for cytokine recognition. J Biol Chem 279:9547-9556

[13] Ulloa-Aguirre A, Timossi C, Barrios-de-Tomasi J, Maldonado A, Nayudu P 2003 Impact of carbohydrate heterogeneity in function of follicle-stimulating hormone: studies derived from in vitro and in vivo models. Biol Reprod 69:379-389

[14] Ulloa-Aguirre A, Midgley AR, Jr., Beitins IZ, Padmanabhan V 1995 Follicle-stimulating isohormones: characterization and physiological relevance. Endocr Rev 16:765-787

[15] Chappel SC, Ulloa-Aguirre A, Ramaley JA 1983 Sexual maturation in female rats: timerelated changes in the isoelectric focusing pattern of anterior pituitary folliclestimulating hormone. Biol Reprod 28:196-205

[16] Ulloa-Aguirre A, Coutifaris C, SC. C 1983 Multiple species of FSH are present within hamster anterior pituitary cells cultured in vitro. Acta Endocrinol Copen 102:343-350

[17] Bousfield GR, Butnev VY, Bidart JM, Dalpathado D, Irungu J, Desaire H 2008 Chromatofocusing fails To separate hFSH isoforms on the basis of glycan structure. Biochemistry 47:1708-1720 
[18] Chappell SC, Bethea CL, Spies HG 1984 Existence of multiple forms of folliclestimulating hormone within anterior pituitaries of cynomolgus monkeys. J Primatol 14:177-194

[19] Ulloa-Aguirre A, Espinoza R, Damian-Matsumura P, Larrea F, Flores A, Morales L, Dominguez R 1988 Studies on the microheterogeneity of anterior pituitary folliclestimulating hormone in the female rat: isoelectric focusing throughout the estrous cycle. Biol Reprod 38:70-78

[20] Smith PL, Kaetzel D, Nilson J, Baenziger JU 1990 The sialylated oligosaccharides of recombinant bovine lutropin modulate hormone bioactivity. J Biol Chem 265:874-881

[21] Grossmann M, Szkudlinski MW, Tropea JE, Bishop LA, Thotakura NR, Schofield PR, Weintraub BD 1995 Expression of human thyrotropin in cell lines with different glycosylation patterns combined with mutagenesis of specific glycosylation sites. J Biol Chem 270:29378-29385

[22] Matzuk MM, Keene JL, Boime I 1989 Site specificity of the chorionic gonadotropin Nlinked oligosaccharides in signal transduction. J Biol Chem 264:2409-2414

[23] Bishop LA, Robertson DM, Cahir N, Schofield PR 1994 Specific roles for the asparaginelinked carbohydrate residues of recombinant human follicle stimulating hormone in receptor binding and signal transduction. Mol Endocrinol 8:722-731

[24] Arey BJ, Stevis PE, Lopez FJ 1997 Induction of promiscuous G protein coupling of the follicle-stimulating hormone (FSH) receptor: a novel mechanism for transducing pleiotropic actions of FSH isoforms. Mol Endocrinol 11:517

[25] Bousfield GR, Butnev VY, Butnev VY, Nguyen VT, Gray CM, Dias JA, MacColl R, Eisele L, Harvey DJ 2004 Differential effects of subunit asparagine56 oligosaccharide structure on equine lutropin and follitropin hybrid conformation and receptor-binding activity. Biochemistry 43:10817-10833

[26] Foord SM, Bonner TI, Neubig RR, Rosser EM, Pin J-P, Davenport AP, Spedding M, Harmar AJ 2005 International Union of Pharmacology. XLVI. G Protein-Coupled Receptor List. Pharmacol Rev 57:279-288

[27] Heckert LL, Daley IJ, Griswold MD 1992 Structural organization of the folliclestimulating hormone receptor gene. Mol Endocrinol 6:70-80

[28] Sprengel R, Braun T, Nikolics K, Segaloff DL, Seeburg PH 1990 The testicular receptor for follicle stimulating hormone: structure and functional expression of cloned cDNA. Mol Endocrinol 4:525-530

[29] Davis D, Liu X, Segaloff DL 1995 Identification of the sites of N-linked glycosylation on the follicle- stimulating hormone (FSH) receptor and assessment of their role in FSH receptor function. Mol Endocrinol 9:159-170

[30] Davis DP, Rozell TG, Liu X, Segaloff DL 1997 The six N-linked carbohydrates of the lutropin/choriogonadotropin receptor are not absolutely required for correct folding, cell surface expression, hormone binding, or signal transduction. Mol Endocrinol 11:550-562

[31] Davis DP, Segaloff DL, Ravi Iyengar and John DH 2002 N-linked carbohydrates on G protein-coupled receptors: mapping sites of attachment and determining functional roles. In: Methods in Enzymol Academic Press; 200-212 
[32] Ascoli M, Fanelli F, Segaloff DL 2002 The lutropin/choriogonadotropin receptor, a 2002 perspective. Endocr Rev 23:141-174

[33] Hanoune J, Defer N 2001 Regulation and role of adenylyl cyclase isoforms. Ann Rev of Pharmacol Toxicol 41:145-174

[34] Cali JJ, Parekh RS, Krupinski J 1996 Splice variants of type VIII adenylyl cyclase. J Biol Chem 271:1089-1095

[35] Insel PA, Head BP, Ostrom RS, Patel HH, Swaney JS, Tang C-M, Roth DM 2005 Caveolae and lipid rafts: $\mathrm{G}$ protein-coupled receptor signaling microdomains in cardiac myocytes. Annals New York Acad Sci 1047:166-172

[36] Beazely MA, Watts VJ 2006 Regulatory properties of adenylate cyclases type 5 and 6: a progress report. Eur J Pharmacol 535:1-12

[37] Pagano M, Clynes MA, Masada N, Cirulea A, Ayling L-J, Wachten S, Cooper DMF 2009 Insights into the residence in lipid rafts of adenylyl cyclase AC8 and its regulation by capacitative calcium entry. Am J Physiol 296:C607-C619

[38] Wu G-C, Lai H-L, Lin Y-W, Chu Y-T, Chern Y 2001 N-Glycosylation and residues Asn805 and Asn890 are involved in the functional properties of type VI adenylyl cyclase. J Biol Chem 276:35450-35457

[39] Cumbay MG, Watts VJ 2004 Novel regulatory properties of human type 9 adenylate cyclase. J Pharmacol Exp Ther 310:108-115

[40] Ohtsubo K, Chen MZ, Olefsky JM, Marth JD Pathway to diabetes through attenuation of pancreatic beta cell glycosylation and glucose transport. Nature Med 17:1067-1075

[41] Wells L, Vosseller K, Hart GW 2001 Glycosylation of nucleocytoplasmic proteins: signal transduction and O-GlcNAc. Science 291:2376-2378

[42] D'Alessandris C, Andreozzi F, Federici M, Cardellini M, Brunetti A, Ranalli M, Del Guerra S, Lauro D, Del Prato S, Marchetti P, Lauro R, Sesti G 2004 Increased Oglycosylation of insulin signaling proteins results in their impaired activation and enhanced susceptibility to apoptosis in pancreatic $\hat{I}^{2}$-cells. FASEB J

[43] Maggi D, Andraghetti G, Carpentier J-L, Renzo C 1998 Cys $^{860}$ in the extracellular domain of insulin receptor $b$-subunit is critical for internalization and signal transduction. Endocrinology 139:496-504

[44] Kenakin T 2007 Functional selectivity through protean and biased agonism: who steers the ship? Mol Pharmacol 72:1393-1401

[45] Grewal N, Nagpal S, Chavali GB, Majumdar SS, Pal R, Salunke DM 1997 Ligandinduced receptor dimerization may be critical for signal transduction by choriogonadotropin. Biophys J 73:1190-1197

[46] Bousfield GR, Butnev VY, Butnev VY, Nguyen VT, Gray CM, Dias JA, MacColl R, Eisele L, Harvey DJ 2004 Differential effects of a subunit asparagine56 oligosaccharide structure on equine lutropin and follitropin hybrid conformation and receptor-binding activity. Biochemistry 43:10817-10833

[47] Arey B 2008 Allosteric modulators of glycoprotein hormone receptors: discovery and therapeutic potential. Endocrine 34:1-10

[48] Munshi R, Linden J 1989 Co-purification of A1 adenosine receptors and guanine nucleotide-binding proteins from bovine brain. J Biol Chem 264:14853-14859 
[49] Kimura K, White BH, Sidhu A 1995 Coupling of human D-1 dopamine receptors to different guanine nucleotide binding proteins: evidence that D-1 dopamine receptors can couple to both Gs and G(o). J Biol Chem 270:14672-14678

[50] Arey BJ, Yanofsky SD, Claudia Perez M, Holmes CP, Wrobel J, Gopalsamy A, Stevis PE, Lopez FJ, Winneker RC 2008 Differing pharmacological activities of thiazolidinone analogs at the FSH receptor. Biochem Biophys Res Comm 368:723-728

[51] Logsdon NJ, Jones BC, Allman JC, Izotova L, Schwartz B, Pestka S, Walter MR 2004 The IL-10R2 binding hot spot on IL-22 is located on the N-terminal helix and is dependent on N-linked glycosylation. J Molec Biol 342:503-514

[52] Saremba S, Nickel J, Seher A, Kotzsch A, Sebald W, Mueller TD 2008 Type I receptor binding of bone morphogenetic protein 6 is dependent on $\mathrm{N}$-glycosylation of the ligand. FEBS J 275:172-183

[53] Nguyen VT, Singh V, Butnev VY, Gray CM, Westfall S, Davis JS, Dias JA, Bousfield GR 2003 Inositol phosphate stimulation by LH requires the entire a Asn56 oligosaccharide. Mol Cell Endocrinol 199:73-86

[54] Matzuk MM, Keene JL, Boime I 1989 Site specificity of the chorionic gonadotropin Nlinked oligosaccharides in signal transduction. J Biol Chem 264:2409-2414

[55] Roess DA, Horvat RD, Munnelly H, Barisas BG 2000 Luteinizing Hormone Receptors Are Self-Associated in the Plasma Membrane. Endocrinology 141:4518-4523

[56] Darling RJ, Kuchibhotla U, Glaesner W, Micanovic R, Witcher DR, Beals JM 2002 Glycosylation of Erythropoietin Affects Receptor Binding Kinetics:â€\%o Role of Electrostatic Interactions. Biochemistry 41:14524-14531

[57] Kenakin T, Miller LJ 2010 Seven transmembrane receptors as shapeshifting proteins: the impact of allosteric modulation and functional selectivity on new drug discovery Pharmacol Rev 62:265-304 